\title{
View from the Chair
}

Jerky, intense, almost

breathless at times, it seems to railroad us into plunging into the perceptions that make up all our realities without pause for logical thought

Mike Grace m.grace.bdj@bda-dentistry.org.uk
$\mathbf{T}$ his issue of the BDJ contains the I3Ist View from the Chair article, a 'bumper' two-page spread on The Christmas Panto for our Christmas Issue of the BDJ. One hundred and thirty one articles over the last nine years is quite a record, and a 'not insubstantial' achievement for the author, Stephen Hancocks. After all this time I felt a review of the philosophy behind 'View' (as it is affectionately known at BDJ production meetings) was highly appropriate.

Do people read and enjoy it? Anecdotally, both Stephen and I receive comments which suggest people do, and some even admit (albeit slightly guiltily) that View from the Chair is the first thing they read on opening their copy of the $B D J$. I have learned to live with this.

View has a unique style which has definitely developed over the years. Jerky, intense, almost breathless at times, it seems to railroad us into plunging into the perceptions that make up all our realities without pause for logical thought. In other words, it reflects what real thinking is about. In real life people do not move gently and carefully along clear lines of thought and interaction, that only happens in fictional stories and plays. We flit from idea to idea, we lose track of our train of thought even as we speak to others, we spend our time focusing on what we are saying when we should be listening. View has the courage to reflect that reality.

Perhaps of more importance, is there any value in reading it? Apart from the fact that this opens up a potential Pandora's Box (or minefield depending on your respect for metaphors) of questions about the value of reading anything at all, this is the question that itches away at all published authors, 'Do people realise the value of reading what I have written?' This is also a question worth asking for any editor when contemplating what to publish.

To answer my own question on the value of View from the Chair I need to go right back to 1992 when Stephen and I were discussing the column and deciding on the name. We wanted the column to have a slightly different perspective on dentistry from the rest of the $B D J$, as if seen from outside or (more poetically) as if someone had just lifted the curtain to peer inside for a brief moment and then gone away with a different understanding than before. Hence the 'Chair'in the title could be taken as the patient's chair, as the patient's view of everything dental is very different from the view everyone else in the dental team has.

Once you realise this, which we have never really explained until now, then the value leaps out at you. We need to be constantly reminded that the world as we see it is not necessarily the same world that everyone else sees. After all, the world the dental nurse sees is very different from the world the dentist sees, and so on through everyone involved in dentistry. Every now and again in normal life we glimpse this alternate reality of another person for a moment, but then it has gone. We are back in our own comfortable environment, where we are the creator of our own reality. We have lost the opportunity to really understand the view from someone else's perspective, and thus we have lost the ability to truly understand what life is like for others.

To me, that is the strength of View from the Chair, its ability to draw us gently out of our comfort zone of familiarity into another reality, if we choose to go. Once outside we can change our thinking to reflect our new perspective, which will in turn lead to changes in what we do. Thus we learn, and with that learning comes progress.

It may sound a little 'grand' for a column that is amusing, critical, at times meandering and always has the ability to make people laugh out loud, but then isn't that the whole point? 